\title{
Adolescent Consent for HPV Vaccine: Ethical, Legal, and Practical Considerations
}

\section{Gregory D. Zimet, PhD}

Department of Pediatrics, Indiana University School of Medicine, Indianapolis, IN, USA

\section{Ross D. Silverman, JD, MPH}

Department of Health Policy and Management, Indiana University Richard M. Fairbanks School of Public Health, and Indiana University Robert H. McKinney School of Law, Indianapolis, IN, USA

\section{Robert A. Bednarczyk, PhD}

Hubert Department of Global Health and Department of Epidemiology, Emory University Rollins School of Public Health, Cancer Prevention and Control Program, Winship Cancer Institute, Emory University, and Emory Vaccine Center, Emory University, Atlanta, GA, USA

\section{Abigail English, JD}

Center for Adolescent Health \& the Law, Chapel Hill, NC, USA

Correspondence: Gregory D. Zimet, PhD, Division of Adolescent Medicine, Department of Pediatrics, Indiana University School of Medicine, 410 W. 10 ${ }^{\text {th }}$ Street, HS 1001, Indianapolis, IN U.S.A. 46202 Tel: (317) 274-8812Ｅmail: gzimet@iu.edu

Keywords: Immunization, Adolescence, Minor Consent, Laws

G.Z. has received consulting fees from Sanofi Pasteur for work on the Adolescent Immunization Project, from Merck for work on HPV vaccination, and from Moderna for work on SARS-CoV-2 vaccination (all outside of the current work), and through Indiana University, has also received investigator-initiated grant funding from Merck related to HPV vaccination. R.B. was supported in part by $\mathrm{NCl}$ grant $1 \mathrm{R} 37$ CA234119-01. The other authors declare no conflicts of interest.

This is the author's manuscript of the article published in final edited form as: 
We address ethical, legal, and practical issues related to adolescent self-consent for HPV vaccination. HPV vaccination coverage continues to lag well-behind the national goal of $80 \%$ series completion. Structural and behavioral interventions have improved vaccination rates, but attitudinal, behavioral, and access barriers remain. A potential approach for increasing access and improving vaccination coverage would be to permit adolescents to consent to HPV vaccination for themselves. We argue that adolescent self-consent is ethical, but that there are legal hurdles to be overcome in many states. In jurisdictions where self-consent is legal, there can still be barriers due to lack of awareness of the policy among healthcare providers and adolescents. Other barriers to implementation of self-consent include resistance from anti-vaccine and parent rights activists, reluctance of providers to agree to vaccinate even when self-consent is legally supported, and threats to confidentiality. Confidentiality can be undermined when an adolescent's self-consented HPV vaccination appears in an explanation of benefits communication sent to a parent or if a parent accesses an adolescent's vaccination record via state immunization information systems. In the context of the COVID-19 pandemic, which has led to a substantial drop in HPV vaccination, there may be even more reason to consider self-consent. The atmosphere of uncertainty and distrust surrounding future COVID-19 vaccines underscores the need for any vaccine policy change to be pursued with clear communication and consistent with ethical principles.

Abbreviations:

$\mathrm{HCP}=$ Healthcare provider

$S T I=$ Sexually transmitted infection

IIS = Immunization information system

VFC $=$ Vaccines for Children

$E O B=$ Explanation of benefits 
Healthy People 2020 set a goal of $80 \%$ series completion for HPV vaccine. ${ }^{1}$ The 2019 National Immunization Survey-Teen shows that $54.2 \%$ of adolescents aged $13-17$ years were up-to-date with the vaccine series. ${ }^{2}$ Although this coverage level represents an incremental increase over 2018 , it remains well-below the Healthy People goal. Furthermore, HPV vaccine ordering and administration have dropped dramatically during the COVID-19 pandemic. $^{2-4}$

Many structural and behavioral approaches to improving HPV vaccine coverage have been suggested or evaluated, including behavioral interventions targeted to healthcare providers (HCPs) and parents, ${ }^{5-8}$ implementation of practice-wide or system-wide changes (e.g., provider prompts), ${ }^{9}$ and consideration of alternative sites for HPV vaccination (eg, schools, pharmacies, and dental offices). ${ }^{10-14}$

An important additional approach for reducing access barriers to HPV vaccination is permitting adolescents to consent for themselves. Given that a low proportion of adolescents complete the HPV vaccine series by their thirteenth birthday, there is a need for catch-up vaccination into later adolescence ${ }^{15}$ Policies allowing older adolescents to consent to HPV vaccination offers a means to facilitate this catch-up.

Multiple dimensions to adolescent self-consent for HPV vaccination include ethical and legal considerations, messaging challenges, potential unintended consequences (e.g., the potential to generate an anti-vaccine backlash), and implementation barriers, as well as questions of whether selfconsent would increase HPV vaccination rates and special considerations in the context of the COVID-19 pandemic. Many of the legal and ethical issues associated with adolescent self-consent for HPV vaccination were addressed in previous articles. ${ }^{16-18}$ We review the points raised by those articles, but also address other critical issues, namely, arguments against self-consent and responses to them, impediments to implementation of self-consent, and considerations regarding adolescent self-consent for HPV vaccination in the context of COVID-19. 


\section{$\underline{\text { Legal and Ethical Framework }}$}

Informed consent is the active information-sharing and decision-making process for health care, through which a provider engages the patient-and often, in the case of minors, a surrogate decision maker-to discuss the nature of care, its associated benefits, risks and alternatives, while concurrently assessing patient/surrogate decisional capacity and values. This autonomy-facilitating process has roots in both ethics and law. In caring for adolescents, physicians are instructed to increase patient engagement in, and direction of, the medical decision-making process as the patient matures. This process begins with seeking assent from the patient to the care decided upon by the surrogate decision maker. As the patient gets older, the clinician may determine that the patient has developed the capacity independently to navigate an informed consent process for a service like HPV vaccination, which offers significant benefits to the patient and few risks. Although, ideally, the adolescent and the parent/surrogate decision-maker would agree that vaccination is in the patient's best interest, in circumstances where the parent refuses to grant consent, or is unavailable, clinicians may not feel comfortable delivering care to the minor absent clear legal as well as ethical approval. ${ }^{19-21}$

The lack of authority for minors to consent is most often a barrier to vaccination during routine health care visits when parents are absent and during confidential adolescent health care visits. ${ }^{22}$ Additional situations may arise when an adolescent wants to be vaccinated, but a parent objects. ${ }^{23}$ Adolescent health professionals have urged that to overcome barriers minor adolescents should be able to consent for vaccination, consistent with legal requirements, and that all legal options should be explored. ${ }^{16}$ Implementing this recommendation would require expansion of the current legal framework.

State laws determine whether adolescent minors can consent for vaccination. Several state law provisions are relevant. Few state laws expressly authorize minors to consent for vaccination. However, 
other laws may enable them to do so. For example: laws allowing minors who have a certain statussuch as those of a certain age, emancipated minors, or homeless youth-to consent for health care generally; laws allowing minors satisfying specific "mature minor" criteria to consent for their own health care; and laws allowing minors to consent for prevention of sexually transmitted infections (STIs) or for prevention of reportable, infectious, contagious, or communicable diseases (Table I). ${ }^{16}$ Two states have explicitly authorized minors to consent for a specific vaccine: Minnesota allows minors to consent for Hepatitis B immunization; ${ }^{24}$ and New York State Department of Health regulations permit sexually active minors to consent to HPV vaccination "during confidential sexual and reproductive health care visits without consent or knowledge of the parent or guardian." ${ }^{25}$ Philadelphia has authorized minors to consent for immunization to prevent "reportable disease, infection, or condition." ${ }^{26}$ Thus, under the existing legal framework, whether an adolescent minor may consent for vaccination depends on several factors: the age and capacity of the adolescent, the locality in which the adolescent is seeking care, the legal status of the adolescent, and the disease for which vaccination is being administered.

Allowing minor adolescents with decisional capacity to consent to HPV vaccination advances important health care- and public health-related ethical principles. ${ }^{17,18}$ Such policies facilitate autonomy, advancing the ability of adolescents to exercise their agency, ${ }^{17}$ and promote flourishing, enhancing adolescents' collective opportunity to live lives free from a currently common illness-causing virus. They are grounded in health justice and equity, removing a structural barrier to health (parental refusal of a recommended public health intervention) faced by a vulnerable population (adolescents, and in particular adolescents living in households that do not believe their children should receive safe, effective, recommended preventive care). They recognize our interdependence and solidarity in the face of a significant health risk, as HPV vaccination promotes both individual health and community health, preventing the sexual transmission of a virus connected with cancer and other adverse health effects, and reducing the community presence of both the virus and the maladies to which it contributes. 
Finally, such policies communicate a state's commitment to supporting safe, effective, evidencegrounded public health policy in furtherance of socially beneficial public health goals.

Increasingly, state legislatures are considering proposals facilitating minor adolescent consent to vaccination generally, but also encompassing HPV vaccination. In 2019 and 2020, such bills were introduced in at least five state legislatures and in the District of Columbia (Table II). None of these bills became law, but analysis of them suggests an ethical framework for laws expanding minor consent to vaccination. Specifically, four of the six bills expressly included language limiting self-consent to those adolescent minors with capacity for informed consent. Maryland ${ }^{27}$ and Georgia ${ }^{28}$ proposed bills to allow adolescents 16 years of age or older to consent to vaccination without parental consent, although the Maryland bill also would have required a discrete informed consent assessment by the health care practitioner. New York's bill ${ }^{29}$ also required a health care practitioner to determine that the adolescent possessed capacity to consent; however, its bill would have allowed teens 14 and older to make such decisions. New Jersey's bill ${ }^{30}$ would have deemed adolescents 14 and older capable of making vaccination-related decisions and would have authorized such vaccinations to be administered by health care practitioners or properly authorized pharmacists, enhancing opportunities for teens to access such services. Under both the Virginia ${ }^{31}$ and the District of Columbia ${ }^{32}$ bills, there were no formal age limits for a minor to be determined by a health care practitioner to be capable of making informed vaccination-related decisions.

\section{Arguments against self-consent and responses to those arguments}

An argument against allowing minors to consent for their own health care, including vaccinations such as HPV vaccine, is that it contravenes the rights of parents. Generally, parents have the right to make medical decisions for their minor children. However, the requirement of parental consent has not been allowed to stand in the way of adolescent minors receiving care that is essential 
for their own health and protection of public health (e.g. sexual health, mental health, and substance use). In these circumstances, exceptions historically have been carved out in the laws of most states. At the same time, adolescent health professionals encourage minors to involve their parents even when it is not legally required, and many adolescents do so voluntarily. ${ }^{33}$

Facilitating adolescent consent through changes to state laws likely will draw the attention and opposition of anti-vaccination and parental rights groups, who often base their arguments on religious beliefs, moral assertions, and presumed safety concerns. These groups have increased their political and social media presence over the past twenty years and have been a significant contributor to rising rates of vaccine hesitancy in the U.S. and globally. ${ }^{34}$ Proposed revisions to state child vaccination rules regularly result in significant lobbying efforts by vaccine- resistant interest groups, as well as occasional lawsuits challenging such rule changes. However, many states have persisted in the face of such pressures, adopting new laws or regulations that increase public health protection against vaccinepreventable illnesses, despite claims of infringement upon parental and other fundamental rights. ${ }^{35}$ To foster confidence in evidence-grounded vaccine policy, jurisdictional immunization programs should develop and disseminate tools for immunization program staff and HCPs to address these concerns and challenges, should they arise. Further, although it is important to maintain public trust in vaccines, the decision as to whether adolescents should be allowed to self-consent for vaccination should not be determined by the desire to avoid criticism by anti-vaccine or parent rights activists.

Another argument advanced in opposition to self-consent is that adolescents lack the necessary decision-making capacity. However, an average adolescent, especially by middle adolescence, likely possesses capacity to make independent informed decisions about HPV vaccination. ${ }^{21,36} \mathrm{~A}$ determination of decisional capacity requires that a $\mathrm{HCP}$ assess and conclude that the minor adolescent can demonstrate and communicate that they understand the clinical choice before them, appreciate the benefits and risks that service might present, and how their treatment choice connects with their health 
and personal goals. These standards vary dependent upon the complexity of the care to be delivered. By the time patients reach adolescence, clinical standards recommend that they at least be engaged in, and assent to, most decisions about their care. In the case of adolescents having the capacity to make decisions related to HPV vaccination, the near- and long-term benefits and risks associated with receiving the vaccine are likely within the reasoning ability of most adolescents. A 2014 survey of clinicians who treated adolescent patients found that they generally felt comfortable with patients 14 years of age and older making decisions about HPV vaccinations. ${ }^{22}$ However, as current HPV-related Vaccine Information Statements are written at a $10^{\text {th }}$ grade or higher reading level, such materials should be simplified for use with adolescent patients.

A long history of exceptions to the basic rule requiring parental consent for minors' health care has evolved to further the public health and the health of adolescents. These exceptions have allowed minors to consent to their own care in a variety of circumstances and to receive that care confidentially. They are based on ethical principles and on decades of research findings documenting that without confidential access to critically important services and the ability to give their own consent, adolescents will forego or delay care. ${ }^{16,37}$

Although the focus of this paper is the ability of adolescents to consent to vaccination without parental involvement in that decision, this does raise an additional concern. Situations may arise in which a parent wants their adolescent to receive HPV vaccine, but the adolescent disagrees. A competent adolescent age 18 or older would have a clear right to decline. The right to refuse for an adolescent minor has not been explicitly addressed as a legal matter in the vaccine context. As an ethical matter, however - both for clinical care and research - even when a parent has the legal authority to consent, obtaining the adolescent's assent is important, even essential, in furtherance of the principle of respect for persons. ${ }^{17}$ Little is known about the rights of adolescents to decline assent or refuse consent in clinical practice, particularly with respect to refusal of vaccination. Examination of this topic is outside 
of the scope of this current report but should be considered in future ethical and practical examinations of adolescent vaccination practices.

Together with the legal and ethical issues, it is worth considering whether granting adolescents the right to self-consent will measurably increase HPV vaccination coverage. Unfortunately, few data are available to assess the impact of adolescent self-consent. However, the results of a national study of adolescent HCPs suggested that the lack of self-consent laws would prevent many providers from vaccinating unaccompanied minor adolescents. ${ }^{22}$ Since 2007, Philadelphia has allowed adolescents aged 11-17 years to consent to their own HPV vaccination, ${ }^{26}$ but it is not clear what effect this policy has had on vaccination rates. Prior research has documented adolescents' willingness and interest to be more engaged in vaccination decisions. ${ }^{38,39}$ However, without clear logistical support for this process, including appropriate HCP education on its legality, it is difficult to determine how to bridge that intention-to-action gap. The degree to which self-consent laws are effective likely depends on communication of those laws to HCPs and adolescents, and assurances that HPV vaccination for selfconsenting adolescents can be done at low cost and confidentially.

\section{Impediments to implementation}

In some settings, such as STI clinics in states where adolescent self-consent is allowed during provision of these services (e.g. New York State), there is a clearly defined population of adolescents who may be able to self-consent. Providers and staff in these settings need to be aware of the potential for adolescent self-consent and how to navigate logistical challenges. Given that research studies have shown that a provider recommendation is the strongest predictor of vaccine receipt, ${ }^{40}$ providers in these setting should make the same strong recommendation for HPV vaccination to adolescents, at all clinical encounters, as they would to the parents of adolescents. 
Logistical considerations for self-consent include adolescents' awareness of the need for vaccines $^{38,41}$ and of their right to self-consent. Although adolescent knowledge and attitudes about HPV vaccination have been studied, little is known about their perceptions of self-consent in localities that allow this. Traditionally, health communications campaigns regarding adolescent vaccination have directed their messages to parents, though some adolescents express a desire to be involved in the decision-making process. ${ }^{38,39}$ Although vaccination is not specifically mentioned in the National Health Education Standards, ${ }^{42}$ methods to effect disease prevention, skills to identify and evaluate healthrelated information, and development of decision-making and self-advocacy are called out for students in grades $6-8 .{ }^{42}$ The inclusion of specific vaccination-related education in health education programs should be evaluated, with standards for inclusion of this information developed and promulgated alongside other health promotion activities.

Additional logistical issues arise in other settings, such as pharmacies. State-level laws govern what vaccines can be given, and to whom, by pharmacists. A recent Department of Health and Human Services amendment to the PREP Act for COVID-19 response expands the ability of pharmacists to vaccinate children, however, this amendment focuses on parental consent for vaccination, without addressing issues of adolescent self-consent. Research indicates that pharmacists do not always perceive themselves to have the skills or training to address novel topics that are presented to them (e.g. expedited partner therapy for sexually transmitted infection treatment). ${ }^{43}$ For vaccination, specifically, numerous barriers exist to effective vaccination of adolescents, including lack of involvement in the Vaccines for Children (VFC) program, reporting to state immunization registries, and low demand for non-influenza vaccines in pharmacy settings. ${ }^{44}$ Adding in state-level guidance around self-consent potentially puts another level of burden on pharmacists, and the impact of this, including pharmacists' willingness to add this to their responsibilities, needs to be evaluated. 
Even if adolescent minors are legally allowed to consent for HPV and other vaccines, concerns about confidentiality are likely to persist. From an adolescent's perspective, part of the value of selfconsent is the potential for receiving the services confidentially. Major logistical hurdles may arise in relation to billing and insurance coverage, and with respect to electronic health records, if uncommon but serious adverse events occur during the vaccine delivery process, ${ }^{45,46}$ Although such events are rare, providers should be prepared to hold contingency planning discussions with their patients, given these events' potential significant impact on the ability to protect patient autonomy and confidentiality. When services are billed through insurance, particularly private insurance, the claims routinely result in the issuance of explanations of benefits (EOBs) and other communications that breach confidentiality for this medical action. ${ }^{46}$ The potential for these breaches is less of a concern with Medicaid, because EOBs would not routinely be sent. Although some protection is available under the HIPAA Privacy Rule and a few states have new laws to address this problem, it remains a significant challenge. ${ }^{47}$

In addition to the billing issues described above, immunization records can be obtained from state immunization information systems (IIS) or from schools as part of their immunization verification process, providing another possible avenue for parents to identify if their adolescent received HPV vaccination without parental consent. State IIS are not typically configured to allow restriction of information about vaccinations based on who consented. The impact of a parent discovering that an adolescent child received HPV vaccine without parental consent is unknown, but may be problematic, particularly if a parent opposes vaccination. 


\section{HPV vaccination and self-consent in the context of the COVID-19 pandemic}

Should the COVID-19 pandemic trigger reconsideration of efforts to promote adoption of rules promoting the rights of adolescents to consent to HPV vaccination? Public trust is critical to the success of health care and public health initiatives. ${ }^{48}$ Although the government has been granted broad authority to protect the public's health, especially at the state and local level, states must balance the execution of those duties against concerns that rash or overly strong application of that power may result in lasting public distrust. Furthermore, it is not yet clear what effects national, state, and local COVID-19 response efforts, including the testing and potential approval of a COVID-19 vaccine, will have on trust in other public health initiatives, including adolescent immunization.

Despite these concerns, it seems unwise to forego pursuing public health prevention policies that advance clear public health and ethical goals. ${ }^{49}$ Although questions of efficacy and safety may remain concerning a potential COVID-19 vaccine - especially as such issues pertain to children, who have not yet begun to be enrolled in COVID-19 vaccine trials - the safety, efficacy, and benefits of adolescent vaccination against HPV are well-documented through years of global implementation. ${ }^{50-52}$ There has been a large drop in routine vaccination, including HPV vaccination, in 2020 due to the COVID19 pandemic, relative to the same time period in $2019 .{ }^{4}$ Given that some parents see HPV vaccination as "optional" or "less important", relative to other routine childhood and adolescent vaccines, it is critical that all potential avenues for HPV vaccination are utilized to get adolescents up-to-date. ${ }^{3}$ In locations where adolescent self-consent is allowed for HPV vaccination, this provides a path forward to improve vaccine coverage during the COVID-19 pandemic. However, it needs to be clear where these vaccines can be given (e.g. which states allow pharmacists to administer HPV vaccine with adolescent selfconsent) and to highlight that in local health communications programs. 


\section{Conclusion}

Numerous research opportunities exist to understand the potential for adolescent self-consent for HPV vaccination to improve vaccine coverage. First, in settings where this is allowed, we need to understand the perspectives of HCPs and staff in promoting and providing vaccinations to adolescents without parental consent. Second, it is important that the concerns of parents regarding their adolescents getting vaccinated without parental consent be evaluated. These concerns may relate to HPV vaccine being viewed primarily as an STI vaccine, worries about vaccine safety, personal beliefs about the value of vaccines, and/or parental rights issues. There are potential repercussions to adolescents for taking this step. These risks should not be minimized and should be better understood. Third, we need to achieve a better understanding of logistical barriers, such as VFC participation, IIS data management, and vaccine supply, particularly among non-primary care providers (e.g. public health clinics, STI clinics, pharmacies) where adolescents may seek vaccination.

We have argued that opportunities exist for expanding access to HPV vaccine for adolescents through self-consent, in a manner grounded in ethical principles and consistent with public health priorities. However, effective implementation of self-consent requires support through existing and new state laws, protections to ensure confidentiality across vaccine providers and insurance types, and clear communication to HCPs and adolescents that self-consent is permitted. HCPs also may need training on how to put confidentiality protections in place and encourage adolescents to take an active role in vaccine decision-making. We focused primarily on HPV vaccination, but many of the principles apply, as well, to other adolescent vaccines. However, HPV vaccine prevents a STI, which distinguishes it from the other adolescent vaccines and allows it to be considered as part of broader permissions for adolescents to self-consent for STI prevention services. 
References

[1] U.S. Department of Health and Human Services. Healthy People 2020. Office of Disease Prevention and Health Promotion; 2015. http://www.healthypeople.gov/2020/topicsobjectives/topic/immunization-and-infectious-diseases/objectives. Accessed September 15, 2020. [2] Elam-Evans LD, Yankey D, Singleton JA, Sterrett N, Markowitz LE, Williams CL, et al. National, Regional, state, and selected local area vaccination coverage among adolescents aged 13-17 years United States, 2019. MMWR Morb Mortal Wkly Rep. 2020;69:1109-16.

[3] Gilkey MB, Bednarczyk RA, Gerend MA, Kornides ML, Perkins RB, Saslow D, et al. Getting human papillomavirus vaccination back on track: protecting our national investment in human papillomavirus vaccination in the COVID-19 era. J Adolesc Health. 2020;67:633-4.

DOI: 10.1016/i.jadohealth.2020.08.013.

[4] Santoli JM, Lindley MC, DeSilva MB, Kharbanda EO, Daley MF, Gallloway L, et al. Effects of the COVID19 pandemic on routine pediatric vaccine ordering and administration-United States, 2020. MMWR Morbidity and Mortality Weekly Report. 2020;69:591-3.

[5] Dempsey AF, Pyrznawoski J, Lockhart S, Barnard J, Campagna EJ, Garrett K, et al. Effect of a health care professional communication training intervention on adolescent human papillomavirus vaccination: a cluster randomized clinical trial. JAMA Pediatr. 2018;172:e180016.

[6] Perkins RB, Banigbe B, Fenton AT, O'Grady AK, Jansen EM, Bernstein JL, et al. Effect of a multicomponent intervention on providers' HPV vaccine communication. Hum Vaccin Immunother. 2020. In press. DOI: 10.1080/21645515.2020.1747923.

[7] Scarinci IC, Hansen B, Kim YI. HPV vaccine uptake among daughters of Latinx immigrant mothers: findings from a cluster randomized controlled trial of a community-based, culturally relevant intervention. Vaccine. 2020;38:4125-34. 
[8] Dixon BE, Zimet GD, Xiao S, Tu W, Lindsay B, Church A, et al. an educational intervention to improve HPV vaccination: a cluster randomized trial. Pediatrics. 2019;143:e20181457.

[9] Zimet G, Dixon BE, Xiao S, Tu W, Kulkarni A, Dugan T, et al. Simple and elaborated clinician reminder prompts for human papillomavirus vaccination: a randomized clinical trial. Acad Pediatr. 2018;18:S66S71.

[10] Calo WA, Shah PD, Gilkey MB, Vanderpool RC, Barden S, Doucette WR, et al. Implementing pharmacy-located HPV vaccination: findings from pilot projects in five U.S. states. Hum Vaccin Immunother. 2019;15(7-8):1831-8.

[11] Daley EM, Vamos CA, Thompson E, Vazquez-Otero C, Griner SB, Merrell L, et al. The role of dental providers in preventing HPV-related diseases: a systems perspective. J Dent Educ. 2019;83:161-72.

[12] Salous MH, Bind MA, Granger L, Johnson LB, Welch K, Villa A. An educational intervention on HPV knowledge and comfortability discussing vaccination among oral health care professionals of the American Indian and Alaskan Native population. Hum Vaccin Immunother. 2020. In press. DOI: $\underline{10.1080 / 21645515.2020 .1752595}$.

[13] Vanderpool RC, Breheny PJ, Tiller PA, Huckelby CA, Edwards AD, Upchurch KD, et al. Implementation and evaluation of a school-based human papillomavirus vaccination program in rural kentucky. Am J Prev Med. 2015;49:317-23.

[14] Perkins R, Legler A, Jansen E, Bernstein J, Pierre-Joseph N, Eun T, et al. Improving HPV vaccination rates: a stepped-wedge randomized trial. Pediatrics. 2020:e20192737.

[15] Bednarczyk RA, Ellingson MK, Omer SB. Human papillomavirus vaccination before 13 and 15 years of age: analysis of National Immunization Survey Teen data. J Infect Dis. 2019;220:730-4.

[16] English A, Ford CA, Kahn JA, Kharbanda EO, Middleman AB. Adolescent consent for vaccination: a position paper of the Society for Adolescent Health and Medicine. J Adolesc Health. 2013;53:550-3. 
[17] Agrawal S, Morain SR. Who calls the shots? The ethics of adolescentself-consent for HPV vaccination. J Med Ethics. 2018;44:531-5.

[18] Silverman RD, Opel DJ, Omer SB. Vaccination over parental objection - should adolescents be allowed to consent to receiving vaccines? N Engl J Med. 2019;381:104-6.

[19] American Academy of Pediatrics Committee on Bioethics. Informed consent in decision-making in pediatric practice. Pediatrics. 2016;138:e2 0161484.

[20] Michaud PA, Blum RW, Benaroyo L, Zermatten J, Baltag V. Assessing an adolescent's capacity for autonomous decision-making in clinical care. J Adolesc Health. 2015;57:361-6.

[21] Steinberg L. Does recent research on adolescent brain development inform the mature minor doctrine? J Med Philos. 2013;38:256-67.

[22] Ford CA, Skiles MP, English A, Cai J, Agans RP, Stokley S, et al. Minor consent and delivery of adolescent vaccines. J Adolesc Health. 2014;54:183-9.

[23] C-Span. Ethan Lindenberger Testifies On Why He Got Vaccinated Against His Mother's Will. 2019. https://www.c-span.org/video/?c4784277/ethan-lindenberger-testifies-vaccinated-mothers. Accessed September 16, 2020.

[24] Minn. Stat. Ann. § 144.3441. https://www.revisor.mn.gov/statutes/cite/144.3441. Accessed September 16, 2020.

[25] N.Y. Comp. Codes R. \& Regs. tit. 10, § 23.4. https://regs.health.ny.gov/content/section-234-minors. Accessed September 16, 2020.

[26] City of Philadelphia, Dep't of Public Health, Regulations Governing the Immunization and Treatment of Newborns, Children and Adolescents, § 4(b), 2007.

[27] S.B. 135, 2020 Gen. Assem. (Md. 2020). https://legiscan.com/MD/text/SB135/2020. Accessed September 16, 2020. 
[28] H.B. 615, 2019-2020 Gen. Assem., Reg. Sess. (Ga. 2019). https://legiscan.com/GA/text/HB615/2019. Accessed September 16, 2020.

[29] S.B. 4244-C, 2019-2020 Leg., Reg. Sess. (N.Y. 2019).

https://www.nysenate.gov/legislation/bills/2019/s4244. Accessed September 16, 2020.

[30] S. $3835,218^{\text {th }}$ Leg., Reg. Sess. (N.J. 2019). https://legiscan.com/NJ/text/S3835/id/2032606. Accessed September 16, 2020.

[31] S.B. 104, 2020 Gen. Assem. (Va. 2020). https://legiscan.com/VA/text/SB104/id/2072899. Accessed September 16, 2020.

[32] B. 23-0171, D.C. Council (D.C. 2019). https://lims.dccouncil.us/Legislation/B23-0171. Accessed September 16, 2020.

[33] Ford C, English A, Sigman G. Confidential health care for adolescents: position paper for the Society for Adolescent Medicine. J Adolesc Health. 2004;35:160-7.

[34] World Health Organization. Ten threats to global health in 2019. https://www.who.int/newsroom/spotlight/ten-threats-to-global-health-in-2019. Accessed September 16, 2020.

[35] Silverman RD. The role of law and ethics in recent preparedness and response for vaccinepreventable illness. Public Health Rep. 2020:33354920949532.

[36] Grootens-Wiegers P, Hein IM, van den Broek JM, de Vries MC. Medical decision-making in children and adolescents: developmental and neuroscientific aspects. BMC Pediatr. 2017;17:120.

[37] English A. Appendix G: 25 Years of AYAH Confidentiality Studies-A Bibliography. In: English A, editor. Adolescent \& Young Adults Health Care in Vermont: A Guide to Understanding Consent \& Confidentiality Laws. San Francisco, CA \& Chapel Hill, NC: Adolescent \& Young Adult Health National Resource Center; Center for Adolescent Health \& the Law; 2018. https://nahic.ucsf.edu/wp- 
content/uploads/2019/01/Vermont-AYAH-Confidentiality-Guide Final.pdf. Accessed September 17, 2020.

[38] Herman R, McNutt LA, Mehta M, Salmon DA, Bednarczyk RA, Shaw J. Vaccination perspectives among adolescents and their desired role in the decision-making process. Hum Vaccin Immunother. 2019;15:1752-9.

[39] Alexander AB, Stupiansky NW, Ott MA, Herbenick D, Reece M, Zimet GD. Parent-son decisionmaking about human papillomavirus vaccination: A qualitative analysis. BMC Pediatrics. 2012;12:192. [40] Perez S, Zimet GD, Tatar O, Stupiansky NW, Fisher WA, Rosberger Z. Human papillomavirus vaccines: successes and future challenges. Drugs. 2018;78:1385-96.

[41] Blumenthal J, Frey MK, Worley MJ, Jr., Tchabo NE, Soren K, Slomovitz BM. Adolescent understanding and acceptance of the HPV vaccination in an underserved population in New York City. J Oncol. 2012;2012:904034.

[42] Centers for Disease Control and Prevention. National Health Education Standards.

https://www.cdc.gov/healthyschools/sher/standards/index.htm. Accessed December 8, 2020.

[43] Bednarczyk RA, Nadeau JA, Davis CF, McCarthy A, Hussain S, Martiniano R, et al. Privacy in the pharmacy environment: analysis of observations from inside the pharmacy. J Am Pharm Assoc. 2010;50:362-7.

[44] Immunize Colorado. Successes and Barriers to Pharmacists' Participation in the Vaccines for Children (VFC) Program in the U.S. 2020. https://teamvaccine.com/2020/08/04/successes-and-barriersto-pharmacists-participation-in-the-vaccines-for-children-vfc-program-in-the-u-s/. Accessed September 16, 2020.

[45] Society for Adolescent Health and Medicine, Gray SH, Pasternak RH, Gooding HC, Woodward K, Hawkins K, et al. Recommendations for electronic health record use for delivery of adolescent health care. J Adolesc Health. 2014;54:487-90. 
[46] Society for Adolescent Health and Medicine, American Academy of Pediatrics. Confidentiality protections for adolescents and young adults in the health care billing and insurance claims process. J Adolesc Health. 2016;58:374-7.

[47] English A, Mulligan A, Coleman C. Protecting Patients' Privacy in Health Insurance Billing \& Claims: A Perspective from Six States. 2017. https://www.nationalfamilyplanning.org/file/confidential-covered/State-Profiles-Overview CC-1.pdf. Accessed September 16, 2020.

[48] Khullar D. Do You Trust the Medical Profession? New York Times2018.

https://www.nytimes.com/2018/01/23/upshot/do-you-trust-the-medical-profession.html. Accessed September 16, 2020.

[49] American Public Health Association. Public Health Code of Ethics. 2019. https://www.apha.org/Lmedia/files/pdf/membergroups/ethics/code of ethics. Accessed September 16, 2020.

[50] Arbyn M, Xu L, Simoens C, Martin-Hirsch PPL. Prophylactic vaccination against human papillomaviruses to prevent cervical cancer and its precursors. Cochrane Database Syst Rev. 2018;5(5):CD009069.

[51] Shimabukuro TT, Su JR, Marquez PL, Mba-Jonas A, Arana JE, Cano MV. Safety of the 9-valent human papillomavirus vaccine. Pediatrics. 2019;144.

[52] Ferris DG, Samakoses R, Block SL, Lazcano-Ponce E, Restrepo JA, Mehlsen J, et al. 4-valent human papillomavirus (4vhpv) vaccine in preadolescents and adolescents after 10 years. Pediatrics. 2017;140. 
Table 1. Existing Laws Authorizing Minors to Consent to Vaccination*

\begin{tabular}{|l|l|}
\hline Laws Allowing Minors with a Certain Status to Consent to Health Care Including Vaccination \\
\hline Status & Notes \\
\hline Minors who have attained a specific age & E.g., 14, 15, 16 \\
\hline Emancipated minors & Usually requires court order of emancipation \\
\hline "Mature" minors & $\begin{array}{l}\text { Includes minors who meet statutory criteria of capacity to } \\
\text { give consent }\end{array}$ \\
\hline Minors living apart from parents & May include homeless or runaway youth \\
\hline Minor parents & May authorize consent for self, for child, or both \\
\hline Married minors & Married minors also considered emancipated \\
\hline Laws Allowing Minors to Consent to Type of Service Encompassing Vaccines \\
\hline Service & Notes \\
\hline Specific vaccine & E.g., MN (Hepatitis B) ${ }^{\#}$, NY (HPV) \\
\hline Prevention of sexually transmitted infections & Generally also allows consent for diagnosis \& treatment \\
\hline $\begin{array}{l}\text { Prevention of reportable, infectious, contagious, or } \\
\text { communicable disease }\end{array}$ & Generally also allows consent for diagnosis \& treatment \\
\hline
\end{tabular}

*Laws vary from state to state. Each of the listed categories is represented in the laws of one or more states; none is found in the laws of every state.

\# Minn. Stat. Ann. § 144.3441.

$\pi$ N.Y. Comp. Codes R. \& Regs. tit. 10, § 23.4 .

Table 2. Proposed Legislation Authorizing Minors to Consent to Vaccination*

\begin{tabular}{|c|c|c|c|c|c|}
\hline \multirow[t]{2}{*}{ State } & \multirow[t]{2}{*}{ Bill No., Year } & \multirow[t]{2}{*}{ Minimum Age } & \multirow{2}{*}{$\begin{array}{l}\text { Clinical Determination } \\
\text { of Capacity to Consent } \\
\text { Explicitly Required }\end{array}$} & \multicolumn{2}{|c|}{ Scope of Consent Authorized } \\
\hline & & & & $\begin{array}{l}\text { Any required or } \\
\text { listed vaccines } \\
\text { including HPV }\end{array}$ & $\begin{array}{l}\text { Any } \mathrm{CDC} \text { or } \mathrm{ACIP} \\
\text { recommended } \\
\text { vaccines }\end{array}$ \\
\hline DC & B 23-0171, 2019 & Any age & $\mathrm{x}$ & & $\mathrm{x}$ \\
\hline GA & HB 615, 2019 & 16 & & $x$ & \\
\hline MD & SB 135, 2020 & 16 & $\mathrm{x}$ & & $\mathrm{x}$ \\
\hline NJ & S 3835, 2020 & 14 & & $x$ & \\
\hline NY & S 4244C, 2019 & 14 & $x$ & & $x$ \\
\hline VA & SB 104, 2020 & Any age & $x$ & & $\mathrm{x}$ \\
\hline
\end{tabular}

* None of the bills had been enacted as of August 2020. 